resolved or improved over time and this was associated with improvements in SF36 summary scores for peripheral neuropathy and mononeuropathy.

Conclusion: PNS disease is an important component of total NPSLE and has a significant negative impact on health related quality of life. The outcome is favourable for most patients, but several factors associated with longer time to resolution were identified.

Disclosure of Interests: John Hanly Consultant for: Eli Lilly Canada, Qiuju Li: None declared, Li Su: None declared, Murray B Urowitz Grant/research support from: GSK, Consultant for: BMS, Celgene, GSK, Lilly, UCB, Caroline Gordon Grant/research support from: Sandwell and West Birmingham Hospitals NHS Trust have received funding from UCB to support research work done by my research group that was unrelated to any pharmaceutical product or clinical trial., Consultant for: I have provided consultancy advice and taken part in scientific advisory boards on the design and analysis of clinical trials and the management of lupus for GSK, EMD Serono and UCB. I have taken part in adjudication and safety monitoring committees for BMS., Speakers bureau: I have been paid by UCB for speaking at meetings., Sang-Cheol Bae: None declared, Juanita Romero-Diaz: None declared, Jorge Sanchez-Guerrero: None declared, Sasha Bernatsky: None declared, Ann E Clarke: None declared, Daniel J Wallace: None declared, David Isenberg: None declared, Anisur Rahman: None declared, Joan T Merrill Grant/research support from: Genentech, UCB, GSK, EMD Serono, Pfizer, Celgene, Exagen, Bristol Myers Squibb, Medimmune/Astra Zeneca, Lilly, Amgen, Xencor, Neovacs, Consultant for: Genentech, UCB, GSK, EMD Serono, Pfizer, RemeGen, Celgene, Exagen, Bristol Myers Squibb, Medimmune/Astra Zeneca, Lilly, Immupharma, Amgen, Janssen, Sanofi, Neovacs, Anthera, Speakers bureau: UCB, GSK, EMD Serono, Bristol Myers Squibb, Medimmune/Astra Zeneca, Janssen, Paul Fortin: None declared, Dafna D Gladman Grant/research support from: AbbVie, Amgen, Celgene, Lilly, Novartis, Pfizer, and UCB, Consultant for: AbbVie, Amgen, BMS, Celgene, Galapagos, Gilead, Janssen, Lilly, Novartis, Pfizer, and UCB, lan N. Bruce Grant/research support from: Genzyme Sanofi, GlaxoSmithKline, Consultant for: AstraZeneca, Eli Lilly, GlaxoSmithKline, ILTOO Pharma, Medlmmune, Merck Serono, Speakers bureau: GlaxoSmithKline, UCB Pharma, Michelle A Petri Shareholder of: Pfizer, Merck, Grant/research support from: AstraZeneca, Exagen, Consultant for: Eli Lilly, GSK, Merck EMD Serono, Janssen, Amgen, Novartis,

Quintiles, Exagen, Inova Diagnostics, AstraZeneca, Blackrock,

Glenmark, UCB, and the Annenberg Center for Health Sciences, Ellen M Ginzler: None declared, M.A. Dooley: None declared, Kristjan Steinsson: None declared, Rosalind Ramsey-Goldman: None declared, Asad A Zoma: None declared, Susan Manzi: None declared, Ola Nived: None declared, Andreas Jonsen: None declared, Munther Khamashta: None declared, Graciela S Alarcon: None declared, Ronald F van Vollenhoven: None declared, Elisabet Svenungsson: None declared, Cynthia Aranow: None declared, Meggan Mackay: None declared, Guillermo Ruiz-Irastorza: None declared, Manuel Ramos-Casals: None declared, S. Sam Lim: None declared, Murat Inanc: None declared, Kenneth C Kalunian: None declared, Soren Jacobsen: None declared, Christine Peschken Consultant for: AstraZeneca, Diane L Kamen: None declared, Anca Askanase: None declared, Chris Theriault: None declared, Vernon Farewell: None declared DOI: 10.1136/annrheumdis-2019-eular.1820

\section{OP0253 WORLDWIDE TRENDS IN MORTALITY OF SYSTEMIC LUPUS ERYTHEMATOSUS BETWEEN 2000 AND 2015: ANALYSIS OF THE WORLD HEALTH ORGANIZATION DATABASE}

Marc Scherlinger $^{1 *}$, Jean Sibilia ${ }^{2}$, Hervé Devilliers ${ }^{3}$, Laurent Arnaud ${ }^{2}$. ${ }^{1}$ Hôpitaux Universitaires de Bordeaux, Centre National de Référence des Maladies Systémiques Rares Est Sud-Ouest (RESO), Service de rhumatologie, Bordeaux, France; ${ }^{2} \mathrm{CHU}$ de Strasbourg, Centre National de Référence des Maladies Systémiques Rares Est Sud-Ouest (RESO), Service de rhumatologie de Strasbourg, Strasbourg, France; ${ }^{3} \mathrm{CHU}$ de Dijon, Service de Médecine Interne et Maladies Systémiques, Dijon, France

Background: Although diagnosis, treatment and prevention strategies of Sys temic Lupus Erythematosus (SLE) have further improved during the last two decades, the net benefit in term of global SLE-related mortality remains unknown.

Objectives: To describe the worldwide trends in SLE mortality between 2000 and 2015 using data of 125 countries from the World Health Organization (WHO) mortality database. To modelize SLE-related deaths taking into account temporal changes, geographical localization and country wealth.

Methods: We analyzed the WHO mortality database containing cause-specific mortality of participating countries. SLE-related deaths were identified using the international classification of disease 10 (ICD-10, code M32). In all countries which provided data between 2000 and 2015, sex-specific mortality rate was calculated for each year using the WHO reference population database. To have a better understanding of mortality fluctuations, countries were grouped geographically by continents and their nominal gross domestic product (GDP) per capita were retrieved from the United Nation database. A mixed regression model for repeated measures was used to take into account the time factor, GDP per capita and continent in SLE-related death.

Results: Between 2000 and 2015, a total of 97,008 SLE-related deaths occurred in 125 countries, which accounted for $0.021 \%$ of all deaths during the same period. World-wide, the overall mortality rate attributed to SLE remained stable $(p=0.86)$ over the study years. However, we detected significant differences between continents $(p=0.0006)$ with the mortality rate of Africa being significantly higher than that of Europe $(p=0.004)$. There was a significant interaction between the continents and the study years $(p=0.01)$ revealing a strong increase in the mortality rate attributed to SLE in Africa. We found a very strong association between SLE-attributed mortality and the GDP per capita $(p<0.0001)$

Conclusion: We observed drastic differences in the evolution of SLE-related mortality due to country geographic localization, wealth and ethnic factors. SLE related remained stable as a whole but strongly increased in the African continent. Disclosure of Interests: Marc SCHERLINGER: None declared, Jean Sibilia: None declared, Hervé Devilliers: None declared, Laurent Arnaud Consultant for: Alexion, Amgen, AstraZeneca, GSK, Janssen-Cilag, LFB, Lilly, Menarini France, Novartis, Pfizer, Roche-Chugaï, and UCB., Paid instructor for: Alexion, Amgen, AstraZeneca, GSK, Janssen-Cilag, LFB, Lilly, Menarini France, Novartis, Pfizer, Roche-Chugaï, and UCB., Speakers bureau: Alexion, Amgen, AstraZeneca GSK, Janssen-Cilag, LFB, Lilly, Menarini France, Novartis, Pfizer, Roche-Chugaï, and UCB

DOI: 10.1136/annrheumdis-2019-eular.3721

FRIDAY, 14 JUNE 2019

Tackling the challenges of autoimmune/
autoinflammatory conditions in children and young
people.

OP0254

CANAKINUMAB IMPROVES PATIENT-REPORTED OUTCOMES IN PATIENTS WITH RECURRENT FEVER SYNDROMES: RESULTS FROM A PHASE 3 TRIAL (CLUSTER)

Helen J. Lachmann ${ }^{1}$, Bernard Lauwerys ${ }^{2}$, Paivi Miettunen ${ }^{3}$, Tilmann Kallinich ${ }^{4}$, Gerd Horneff $^{5}$, Riva Brik ${ }^{6}$, Rafaelle Manna ${ }^{7}$, Sara Murias $^{8}$, Sinisa Savic ${ }^{9}$, Serge Smeets ${ }^{10}$, Fabrizio De Benedetti ${ }^{11}$, Anna Simon ${ }^{12}$. ${ }^{1}$ University College London Medical School, London, United Kingdom; ${ }^{2}$ Universite catholique de Louvain, Brussels, Belgium; ${ }^{3}$ Alberta Children's Hospital, Calgary, Canada; ${ }^{4}$ Charité Berlin Campus Virchow, Berlin, Germany; ${ }^{5}$ Centre of Paediatric Rheumatology, Sankt Augustin, Germany, ${ }^{6}$ Ruth Rappaport Children Hospital, Haifa, Israel; ${ }^{7}$ Università Cattolica del Sacro Cuore, Rome, Italy; ${ }^{8}$ University Hospital La Paz, Madrid, Spain; ${ }^{9}$ St James's University Hospital, Leeds, United Kingdom; ${ }^{10}$ Novartis Pharma B.V., Arnhem, Netherlands; ${ }^{11}$ Ospedale Pediatrico Bambino Gesú, Rome, Italy; ${ }^{12}$ Radboud University Medical Centre, Nijmegen, Netherlands

Background: Recurrent fever syndromes have a significant impact on healthrelated quality of life (HRQoL). ${ }^{1}$ Canakinumab (CAN) has demonstrated efficacy and safety in patients with colchicine-resistant familial Mediterranean fever (crFMF), hyper-immunoglobulin D syndrome/mevalonate kinase deficiency (HIDS/MKD) and tumour necrosis factor receptor-associated periodic syndrome (TRAPS) in the pivotal, Phase 3, CLUSTER trial (NCT02059291), ${ }^{2}$ but there are limited published data on the impact of CAN on the HRQoL, work/school and social life of these patients.

Objectives: To evaluate effect of CAN on HRQoL, work/school and social life of patients in the 3 disease cohorts (crFMF, HIDS/MKD, and TRAPS) in a double blinded randomised study.

Methods: The detailed study design was reported previously. ${ }^{2}$ The HRQoL of patients treated with CAN was assessed at Baseline (BL), Week 17 (Wk17) and Week 41 (Wk41) in patients who fully responded (absence of flares), either to 150 mg q4w CAN, or to $300 \mathrm{mg} q 4 \mathrm{w}$ CAN after up dosing. Methods used were the Child Health Questionnaire (CHQ)-PF50 physical (PhS) and psychosocial (PsS summary scores (children $>5-<18$ years), Short-Form health survey (SF-12) physical component summary (PCS) and mental component summary (MCS adults $>18$ years) scores. An increase from baseline of 2,5 , and 8 points in the $\mathrm{CHQ}-\mathrm{PF} 50$ physical and psychological component summary scores corresponds to a small, moderate and large treatment effect, respectively. Functional impairment related to work/school, social life and family life/home responsibilities was assessed by Sheehan Disability Scale (SDS). A score of 5 or higher in SDS is associated with significant impairment

Results: Patients showed a high impairment of HRQoL at baseline in all 3 cohorts (crFMF $n=31$, HIDS/MKD $n=37$ and TRAPS $n=22$ ). At Wk17, a moderate to large 